\title{
Evidence for redundancy in cysteine biosynthesis in Rhizobium leguminosarum RL3841: analysis of a cysE gene encoding serine acetyltransferase
}

\author{
G. Parker, D. Walshaw, K. O'Rourke, S. Broad, A. Tingey, \\ P. S. Poole and R. L. Robson
}

Microbiology Division, School of Animal and Microbial Sciences, The University of Reading, Reading RG6 6AJ, UK
Author for correspondence: R. L. Robson. Tel: +44118 9316639. Fax: +441189316562. e-mail: r.l.robson@reading.ac.uk.

A cysE gene encoding a serine acetyltransferase (SAT) potentially involved in the biosynthesis of cysteine was identified $\sim 4 \mathrm{~kb}$ upstream of the previously described aapJQMP gene cluster that encodes an amino acid permease in Rhizobium leguminosarum strain 3841 . The gene exhibits $>40 \%$ identity to the family of SATs containing $\mathrm{N}$-terminal extensions that have been described for other bacteria and plants. The ORF has three possible translation initiation sites which potentially encode polypeptides of 311, 277 and/or 259 amino acid residues, respectively. All three ORFs complemented the cysE mutation in an Escherichia coli cysteine auxotroph, strain JM39. Insertion of Tn5-lacZ into cysE in the genome of $R$. leguminosarum (strain RU632) lowered SAT activity in crude extracts by $>95 \%$. However, RU632 was not a cysteine auxotroph, which suggests that $R$. leguminosarum possesses some redundancy in cysteine biosynthesis. Additional copies of cysE could not be detected in the genome when the $R$. leguminosarum cysE gene was used as a hybridization probe. Therefore it is possible that $R$. leguminosarum possesses an alternative pathway for cysteine biosynthesis which avoids O-acetylserine. Strain RU632 was unaffected in its ability to nodulate Pisum sativum, and the nodules were effective for $\mathrm{N}_{2}$ fixation (measured by $\mathrm{C}_{2} \mathrm{H}_{2}$ reduction). Transcriptional activity of cys $E$ was determined by measuring the $\beta$-galactosidase arising from cysE:: Tn5-lacZ fusions. Maximal levels of expression were observed during early exponential growth and were not influenced by the level of sulphur (supplied as sulphate). However, transcription was repressed by approximately twofold in ammonium-grown, as opposed to glutamate-grown, cultures. Repression by ammonium was not seen in a strain defective for $n t r C$.

Keywords: sulphur metabolism, symbiotic nitrogen fixation, SAT, nodulation

\section{INTRODUCTION}

Members of the soil-dwelling genus Rhizobium form specific $\mathrm{N}_{2}$-fixing symbioses with leguminous plants : the bacterium receives fixed carbon from the plant and supplies fixed nitrogen in return. This exchange of nutrients is highly co-ordinated and involves the in-

Abbreviations: DTNB, 5,5'-dithobis-(2-nitrobenzoic acid); SAT, serine acetyltransferase.

The GenBank accession number for the sequence reported in this paper is AJ271648. duction of specific transport systems in the bacteroid. In the course of an investigation into the mechanisms by which fixed nitrogen compounds may be passed from Rhizobium leguminosarum to the plant, a general Lamino acid transporter was discovered which catalyses high rates of exchange between intracellular and extracellular amino acid pools (Walshaw \& Poole, 1996). The genes encoding this transporter were originally identified on the basis that they increased $\left[{ }^{14} \mathrm{C}\right]$ glutamate uptake when supplied in additional copies in R. leguminosarum. One such clone which conferred this phenotype is pRU3024, a cosmid that contains a relatively large 
Table 1. Bacterial strains and plasmids used in this work

$\mathrm{Str}^{\mathrm{R}}$, streptomycin-resistant; $\mathrm{Amp}^{\mathrm{R}}$, ampicillin-resistant; $\mathrm{Tc}^{\mathrm{R}}$, tetracycline-resistant; $\mathrm{Kan}^{\mathrm{R}}$, kanamycin-resistant.

\begin{tabular}{|c|c|c|}
\hline Strain or plasmid & Phenotype/genotype & Reference/source \\
\hline \multicolumn{3}{|c|}{ Rhizobium leguminosarum } \\
\hline RL3841 & $\operatorname{Str}^{\mathrm{R}}$ derivative of strain 300 & Glenn et al. (1980) \\
\hline RU502 & RL3841(pRU3031) & This work \\
\hline RU504 & RL3841(pRU3033) & This work \\
\hline RU543 & aapJ:: Tn5-lacZ derivative of RL3841 & Walshaw \& Poole (1996) \\
\hline RU632 & cysE::Tn5-lacZ derivative of RL3841 & This work \\
\hline RU929 & $n \operatorname{tr} C:: \Omega$ derivative of RL3841 & Walshaw et al. (1997) \\
\hline RU981 & $n \operatorname{tr} C:: \Omega(\mathrm{pRU} 3031)$ derivative of RL3841 & This work \\
\hline RU982 & $n t r C:: \Omega(\mathrm{pRU} 3033)$ derivative of RL3841 & This work \\
\hline RU1017 & aapJ:: Tn5-lacZ ntrC:: $\Omega$ derivative of RU929 & Walshaw et al. (1997) \\
\hline RU1027 & cysE::Tn5-lacZ $n \operatorname{tr} C:: \Omega$ derivative of RU632 & This work \\
\hline \multicolumn{3}{|l|}{ Escherichia coli } \\
\hline JM39 & $\left(\mathrm{F}^{\prime} c y s E 51\right.$ tfr8) & Jones-Mortimer (1968) \\
\hline DH5 $\alpha$ & $\begin{array}{l}\phi 80 \mathrm{~d} l a c Z \Delta \mathrm{M} 15 \text { recA1 endA1 gyrA96 hsdR17 }\left(\mathrm{r}_{\mathrm{K}}^{-} \mathrm{m}_{\mathrm{K}}^{-}\right) \text {supE44 } \\
\text { relA1 deoR } \Delta(\text { lacZYA-argF) U169 }\end{array}$ & Hanahan (1983) \\
\hline BL21(DE3) & $\begin{array}{l}\mathrm{F}^{-} \text {ompT hsdS } S_{\mathrm{B}}\left(\mathrm{r}_{\mathrm{B}}^{-} \mathrm{m}_{\mathrm{B}}^{-}\right) d c m \text { gal }(\lambda c \mathrm{I} t s 857 \text { ind1 Sam7 nin5 } \\
\text { lacUV5-T7 gene } 1)\end{array}$ & Studier \& Moffat (1986) \\
\hline \multicolumn{3}{|c|}{ Sinorhizobium meliloti } \\
\hline 1021 & SU47 str-21 & Mead et al. (1982) \\
\hline \multicolumn{3}{|l|}{ Plasmid/cosmid } \\
\hline pBluescript SK+ & $\mathrm{Amp}^{\mathrm{R}}$ cloning vector & \\
\hline pTZ18 & $A m p^{R}$ cloning vector & Mead et al. (1986) \\
\hline pT7-7 & $\mathrm{Amp}^{\mathrm{R}} \mathrm{T} 7$ promoter expression vector & Tabor \& Richardson (1985) \\
\hline pRU3024 & $\begin{array}{l}\mathrm{Tc}^{\mathrm{R}}, 15 \mathrm{~kb} \text { genomic segment from RU3841 in pLAFR, cysE } \\
\text { aapJQMP }\end{array}$ & Walshaw \& Poole (1996) \\
\hline pRU3031 & pRU3024, $\mathrm{Tc}^{\mathrm{R}} \mathrm{Km}^{\mathrm{R}} c y s E: \operatorname{Tn} 5-l a c Z$ & This work \\
\hline pRU3033 & pRU3024, $\mathrm{Tc}^{\mathrm{R}} \mathrm{Km}^{\mathrm{R}} c y s E: \operatorname{Tn} 5-l a c Z$ & This work \\
\hline pRU383 & $\begin{array}{l}\text { Amp }^{\mathrm{R}}, 0 \cdot 8 \mathrm{~kb} \text { BamHI fragment with most of } c y s E \text { from } \\
\text { pRU3024 in pBluescript SK+ }\end{array}$ & This work \\
\hline pATRLCE13 & $\mathrm{Amp}^{\mathrm{R}}$, cysE, $3.4 \mathrm{~kb}$ EcoRI fragment from pRU3024 in pTZ18 & This work \\
\hline pSS1 & $\mathrm{Amp}^{\mathrm{R}}, \mathrm{ORF}^{1}$ in $\mathrm{pT} 7-7$ & This work \\
\hline pSS2 & $\mathrm{Amp}^{\mathrm{R}}, \mathrm{ORF}^{2}$ in $\mathrm{pT} 7-7$ & This work \\
\hline pSS3 & $\mathrm{Amp}^{\mathrm{R}}, \mathrm{ORF}^{3}$ in $\mathrm{pT} 7-7$ & This work \\
\hline
\end{tabular}

fragment $(\sim 30 \mathrm{~kb})$ of the $R$. leguminosarum genome. Random Tn5 mutagenesis of pRU3024 led to the localization of an approximately $7 \mathrm{~kb}$ region that was responsible for the enhanced glutamate-uptake phenotype. Insertion mutations in this region abolish enhanced glutamate uptake. When this region was subcloned and sequenced it was found to contain a cluster of four genes (aapJ, aapQ, aapM and $a a p P$ ) that encode polypeptides with a high degree of amino acid sequence identity to components of ATP-binding cassette (ABC) superfamily of transporters (Walshaw \& Poole, 1996). Further analysis established that the aap genes in R. leguminosarum not only enhance the accumulation of a broad range of amino acids, including glutamate, but also affect the efflux of those amino acids directly or independently via a second efflux channel or transporter. The aapJQMP operon in R. leguminosarum was shown to be responsive to nitrogen regulation. In $R$. legumino- sarum, nitrogen status is probably sensed by a mechanism similar to that known for Escherichia coli, in which a uridylyltransferase/uridylyl-removing enzyme senses the ratio of glutamine to $\alpha$-ketoglutarate and changes the uridylylation state of the $\mathrm{P}_{\mathrm{II}}$ protein. This, in turn, alters the ability of NtrB to act either as a kinase or as a phosphatase for the phosphorylation or dephosphorylation of NtrC, which is a transcriptional activator of nitrogen-regulated operons (Patriarca et al., 1993). Mutants in $n t r C$ caused derepression of the aap operon, which induced high rates of amino acid uptake even when the organisms were grown with ammonium as a nitrogen source. Therefore NtrC appears to negatively regulate the aap genes (Walshaw et al., 1997).

This work describes a second locus present on the cosmid pRU3024, in which Tn5 mutations lower the enhanced accumulation of glutamate but, unlike the 
mutations in the aap genes, do not abolish it completely. We show here that the mutations are located in a cysE gene encoding a serine acetyltransferase (SAT), an enzyme which catalyses the first unique step in cysteine biosynthesis.

\section{METHODS}

Strains and media. The strains and plasmids used in this work are listed in Table 1 . E. coli strains were routinely grown at $37^{\circ} \mathrm{C}$ on nutrient agar or broth. To test for cysteine auxotrophy, M9 minimal salts agar (Sambrook et al., 1989) was used and cysteine was added at $60 \mu \mathrm{g} \mathrm{ml}^{-1}$ for growth of cysteine auxotrophs. $R$. leguminosarum strains were grown at $28{ }^{\circ} \mathrm{C}$ on either tryptone yeast extract (TY) (Beringer, 1974) or acid minimal salts (AMS) medium (Poole et al., 1994a). Antibiotics were added, where required, at the following concentrations $\left(\mu \mathrm{g} \mathrm{ml}^{-1}\right)$ : for E. coli strains, ampicillin, 100; kanamycin, 20; and for $R$. leguminosarum strains, streptomycin, 500; kanamycin, 40, tetracycline, 2 in acid minimal salts medium and 5 in tryptone yeast extract medium.

Molecular biology methods. Methods used for preparation of genomic and plasmid/cosmid DNA, restriction analysis, agarose gel electrophoresis, cloning, production of digoxigenin-labelled probes, and automated DNA sequencing using a Pharmacia ALF Express and Cy5-labelled primers were as described by Walshaw \& Poole (1996) or in Parker et al. (1999). Hybridizations were carried out at various stringencies as stated in the text. The PCR reactions were routinely performed with the following cycle: a hot start at $94{ }^{\circ} \mathrm{C}$ for $2 \mathrm{~min}$, then 30 cycles of $1 \mathrm{~min}$ at $94^{\circ} \mathrm{C}$ for, $1 \mathrm{~min}$ at $60^{\circ} \mathrm{C}$ and $1.5 \mathrm{~min}$ at $65^{\circ} \mathrm{C}$, after which samples were chilled at $4{ }^{\circ} \mathrm{C}$. The cloning primers for the PCR were as follows: RLCEM1，5'-CGAAAACATATGCTAAAAAACCATGGC3'; RLCEM2, 5'-AACGAGGAGAGCGCATATGGTCGC3'; RLCEM3, 5'-CCGCTGAAGCATATGGATCCC-3'; RLCEND1， 5'-GGCCCTCCCCGCTCGGATCCCGCCG3'; RLCEND1B，5'-GGCCCTCCCCGCTCAGATCTCGCCG'3' (restriction sites underlined). The DNA sequencing primers were as follows: RLCER, 5'-CAATGGGCGAGACGATGTGT-3'; RLCER2, 5'-TGGTGCCGACGCCGATCAGC-3'; RLCEF, 5'-CCAAGATCCTCGGCAATATC-3' ; Tn5 primer, 5'-GGATCCATAATTTTTTCCTCC-3'.

Bacterial genetic methods. The transformation of E. coli with plasmids, the conjugation in $R$. leguminosarum, the procedures for Tn5-lacZ mutagenesis, and the homogenotization of mutations into the genome of $R$. leguminosarum were as described by Walshaw \& Poole (1996).

Bioinformatics. Protein-similarity searches were performed using BLAST or $\psi$-BLAST (Altschul et al., 1997), using the server for The National Centre for Biotechnology Information (http://www. ncbi.nlm.nih.gov/blast/blast.cgi). Multiple sequence alignments were carried out using MULTALIN (Corpet, 1988) at the Server of the Institut National de la Recherche Agronomique (http://www.jouy.inra.fr/) or CLUSTAL w (Thompson et al., 1994) at the server of the European Bioinformatics Institute (http://www2.ebi.ac.uk/clustalw/). Protein relationships were determined using the neighbourjoining method of Saitou \& Nei (1987), and the relational cluster diagram constructed from these analyses was drawn using TREEVIEW (http://taxonomy.zoology.gla.ac.uk/rod/ treeview.html). Searches for protein targeting signals were conducted using SIGNALP (Nielsen et al., 1997: http://www/ cbs.dtu.dk/services/SignalP).
Measurement of enzyme activities and protein contents. SAT activity was measured spectrophotometrically in a realtime assay at $30^{\circ} \mathrm{C}$ by following the serine-dependent cleavage of acetyl-CoA in the presence of DTNB, essentially as described by Kredich \& Tomkins (1966). Units are defined as nmol (mg protein $)^{-1} \mathrm{~min}^{-1}$. $\beta$-Galactosidase activity was measured essentially as described by Miller (1972) but with the modifications (for R. leguminosarum) of Poole et al. (1994b). Protein contents were measured using Folin-Ciocalteu reagent with BSA as the standard.

Determination of nodulation and nitrogen fixation. Nodulation and $\mathrm{N}_{2}$ fixation in nodules was determined in triplicate as described by Trinick et al. (1976). $\mathrm{N}_{2}$-fixation activity was expressed as $\mu \mathrm{mol} \mathrm{C}_{2} \mathrm{H}_{2}$ reduced $\mathrm{h}^{-1}$ per plant.

\section{RESULTS AND DISCUSSION}

\section{Mutations in pRU3024 affecting enhancement of glutamate uptake in $R$. leguminosarum}

Cosmid pRU3024 (Fig. 1) was described previously and contains the aap gene cluster within a segment of approx. $30 \mathrm{~kb}$ of the genome of $R$. leguminosarum strain 3841 cloned into pLAFR1. When introduced into $R$. leguminosarum, pRU3024 enhanced the accumulation of $\left[{ }^{14} \mathrm{C}\right]$ glutamate by more than sixfold in organisms grown in a nitrogen-sufficient medium. Only insertions of $\operatorname{Tn} 5:$ : lac $Z$ into the aap cluster completely abolish the enhanced glutamate-uptake phenotype, but the insertions in plasmids pRU3031 and pRU3033 located 3.4 and $4 \mathrm{~kb}$ upstream of the aap gene cluster lower the enhancement of glutamate uptake by approximately $2 \cdot 5$-fold (Walshaw \& Poole, 1996).

Analysis of DNA sequences immediately flanking the Tn5-lacZ insertions in plasmids pRU3031 and pRU3033 indicated that both insertions disrupt a gene with high sequence identity to $c y s E$ genes from bacteria such as $E$. coli and Azotobacter sp. and from plants such as Arabidopsis. A $3.4 \mathrm{~kb}$ EcoRI fragment from pRU3024 covering the sites of insertions in pRU3031 and pRU3033 was subcloned into pTZ18 to give plasmid pATRLCE13. The DNA sequence for $2712 \mathrm{bp}$ of this fragment was determined. Within this region, two ORFs were found which have codon usages consistent with other genes from R. leguminosarum. ORF1 is preceded by a good potential ribosome-binding site and encodes a polypeptide of 261 amino acid residues showing significant identity to a family of bifunctional enzymes with both esterase and halogenoperoxidase activities. A second ORF (ORF2A) of $936 \mathrm{bp}$ was located $36 \mathrm{bp}$ downstream of ORF1 (Fig. 2). ORF2A encodes a polypeptide of 311 amino acid residues with $>40 \%$ identity to SATs from a wide variety of bacteria and plants (Fig. 3), the closest relatives being the CysE2 and CysE4 from Arabidopsis thaliana (Fig. 4). Alternative potential translation initiation sites are located 129 and $183 \mathrm{bp}$ $3^{\prime}$ to ORF1, giving ORF2B and ORF2C, which encode shorter polypeptides of 277 and 259 residues, respectively. Of the three potential translation initiation sites, only that of ORF2B (5'-AACGAGGAGAGCGGCG ATG- $3^{\prime}$ ) is significantly purine rich and conforms well 


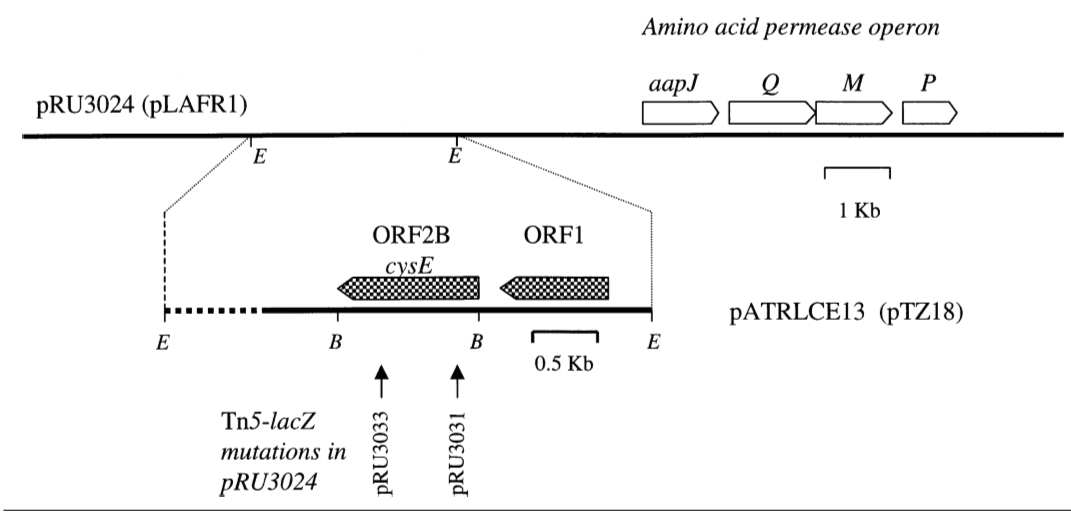

Fig. 1. Location and cloning of the $c y s E$ gene from $R$. leguminosarum 3841. The figure shows the location and orientation of ORF1 and ORF2B (cysE) relative to the aapJQMP cluster previously described for cosmid pRU3024. The $3.4 \mathrm{~kb}$ EcoRI fragment of pRU3024 bearing these genes was cloned into pTZ18 to give plasmid pATRCE13 (shown in the lower part of the figure). The extent of the DNA sequence obtained for this fragment is shown by the continuous line. The sites of Tn5-lacZ mutations in cysE in the plasmids pRU3031 and pRU3033 are indicated. The mutation in pRU3031 was selected for most of the phenotypic analysis and for the construction of the chromosomal homegenote, since it is located closest to the $\mathrm{N}$-terminal coding region of the gene.
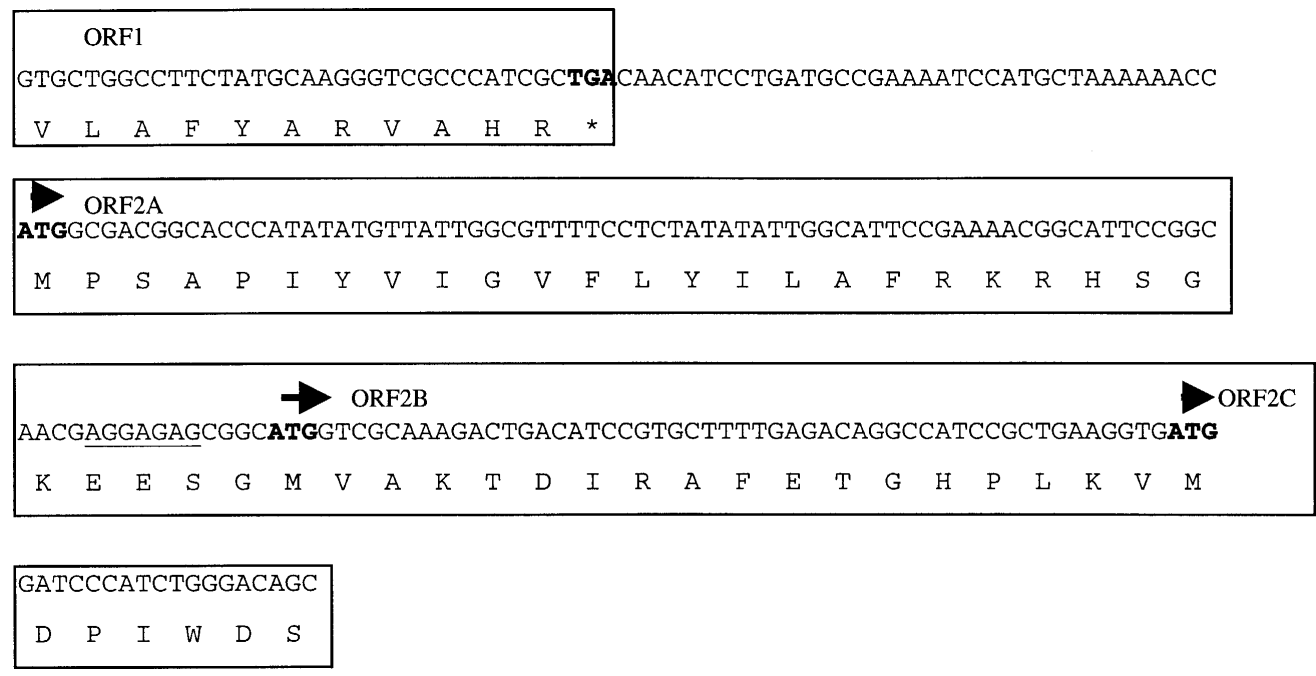

Fig. 2. The nucleotide sequence for the region containing parts of ORF1 and ORF2. The sequence of a region extending from base 983 to base 1221 from within the 2712 bp of the sequenced portion of the insert in pATRLCE is shown. The deduced C-terminal amino acid sequence of ORF1 and potential alternative N-terminal sequences for ORF2 are shown using single-letter notation. The potential alternative translation starts for ORF2 are indicated by the arrows starting at positions 1041 (ORF2A), 1147 (ORF2B) and 1201 (ORF2C). Codon usage does not allow discrimination of the most likely translation product in vivo, but only ORF2B is preceded by a convincing potential ribosome-binding site starting at position 1135 (underlined).

to the consensus sequence for potential ribosomebinding sites observed in other R. leguminosarum genes. Sequence analysis revealed a potential transcription terminator located $31 \mathrm{bp}$ downstream of ORF2. No other significant matches at the DNA or protein levels were found in the sequences flanking ORFs 1 and 2. ORF1 and ORF2 are organized in such a way that they could be co-transcribed, but this remains to be established.

SAT catalyses the acetyl-CoA-dependent acetylation of serine, giving $\mathrm{O}$-acetylserine, which serves as the acceptor for sulphide in the biosynthesis of cysteine catalysed by $\mathrm{O}$-acetylserine-thiol lyase. SAT-encoding genes are found in eubacteria, microfungi, algae, higher plants and some protozoa but not in the Archaea or higher animals. In the enteric bacteria E. coli and Salmonella typhimurium, SAT is rate limiting for cysteine biosynthesis and is subject to feedback inhibition by cysteine. Also, O-acetylserine acts as a coactivator in the genetic control of the expression of proteins and enzymes involved in the assimilation of sulphur via the assimilatory sulphate-reduction pathway (Kredich, 1987). Irrespective of which of the three ORFs is correct, the SAT encoded by the R. leguminosarum gene clearly belongs to one of the three known SAT families. All members have a relatively high degree of identity extending over approximately 170 residues (which probably constitutes the catalytic core of the enzyme). Group 1 SATs contain little more than this 


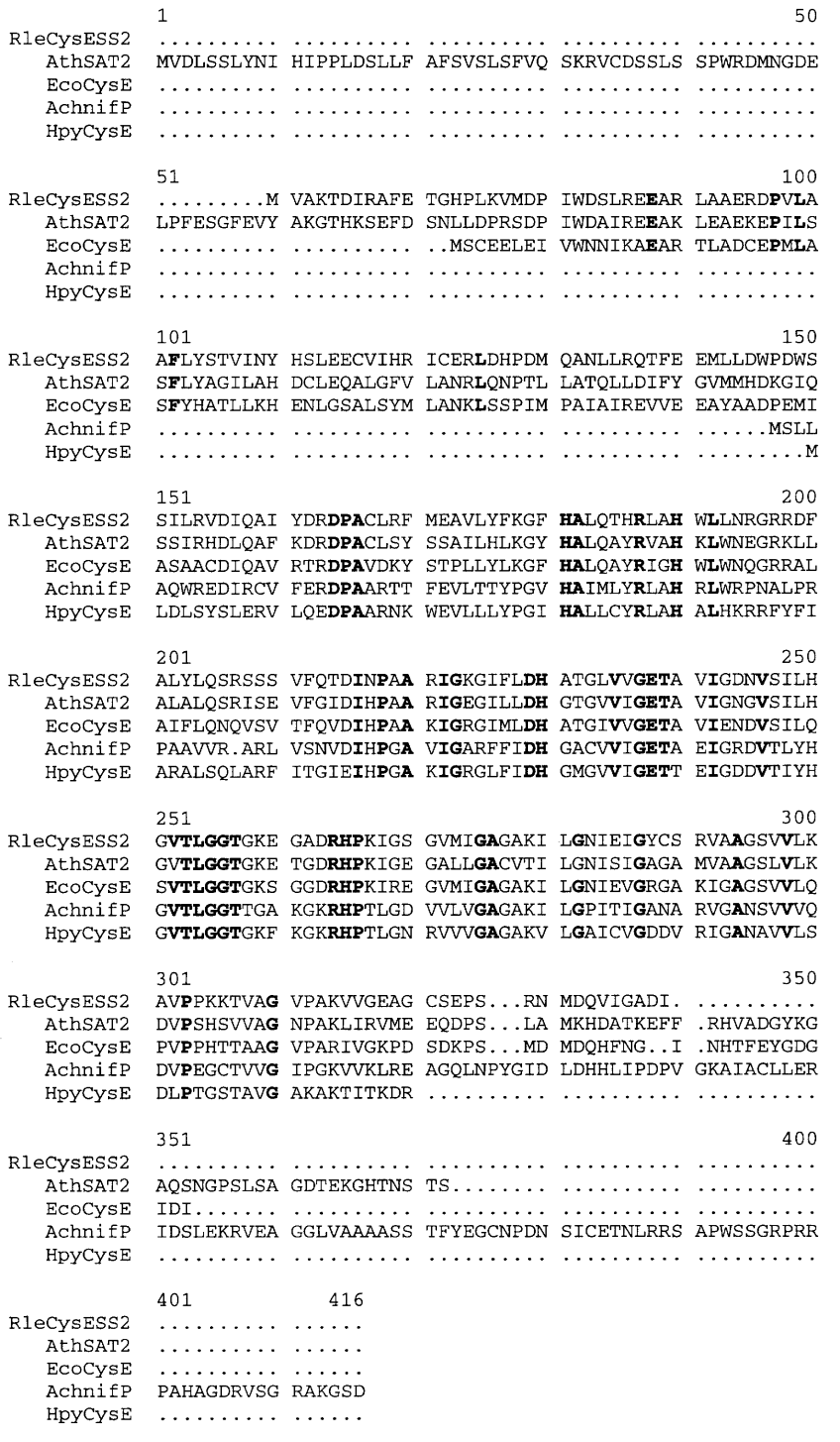

Fig. 3. Multiple alignments of amino acid sequences of SATs of bacterial and plant origin. The sequences are as follows: RleCysESS2, ORF2B from R. leguminosarum; HpyCysE, putative SAT from Helicobacter pylori (type 1 SAT); AchnifP, SAT from the $\mathrm{N}_{2}$-fixation gene cluster of Azotobacter chroococcum (type 3 SAT with C-terminal extension), EcoCysE, SAT from $E$. coli (type 2 SAT with $\mathrm{N}$-terminal extension), AthSAT2, SAT 2 from $A$. thaliana (type 2 SAT with $\mathrm{N}$-terminal extension including $\mathrm{N}$ terminal targeting sequence). Amino acid residue identities are shown in bold.

conserved core, whereas group 2 SATs, including the example identified here, contain N-terminal extensions of between 40 and 200 amino acid residues. Group 3 SATs lack the long $\mathrm{N}$-terminal extensions but have significant C-terminal extensions. The $\mathrm{N}$-terminal domains of the group 2 SATs from plants are likely to be chloroplast target signals. This possibility was worth considering in the case of $R$. leguminosarum because of the plant-bacterium symbiosis, but when the three ORFs were subjected to analysis using the SIGNALP

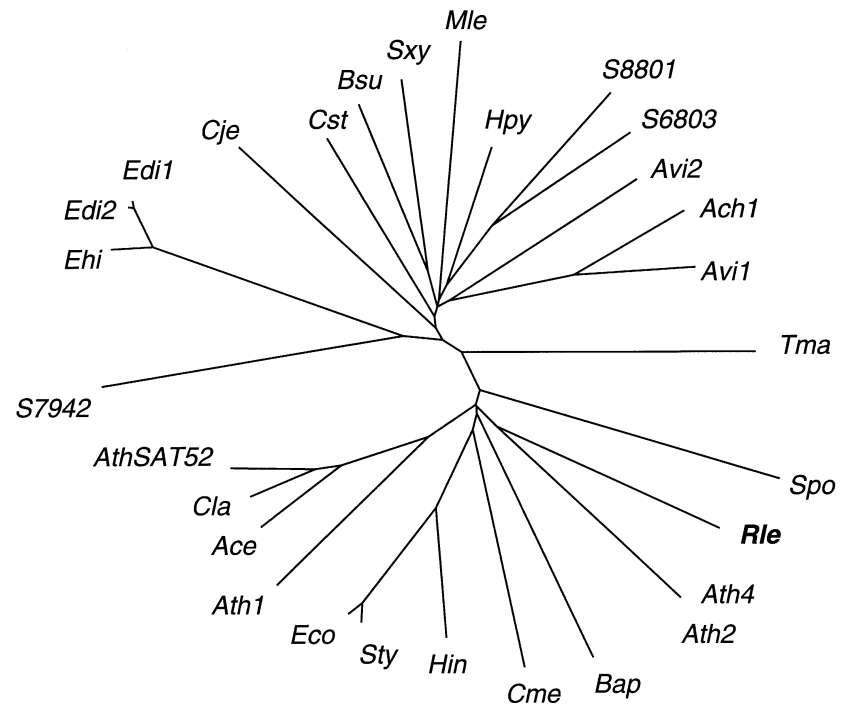

Fig. 4. Inter-relationships of serine acetyltransferases from different sources. The methods for multiple alignment and reconstruction of the unrooted phylogenetic tree are described in the text. The sources of the SAT amino acid sequences are as follows: Ace, Allium cepa (onion); Ach1, Azotobacter chroococcum nifP; Ath1, Ath2, Ath4 and AthSAT52, A. thaliana isoforms; Avi1 and Avi2, Azotobacter vinelandii; Bap, Buchnera aphidicola; Bsu, Bacillus subtilis; Cme, Cyanidioschyzon merolae (red alga, chloroplast isoform); Cla, Citrullus lanatus (water melon); Cje, Campylobacter jejuni; Cst, Clostridium sticklandii; Eco, Escherichia coli; Edi1 and Edi2, Entamoeba dispar isoforms; Ehi, Entamoeba histolytica; Hin, Haemophilus influenzae; Hpy, Helicobacter pylori; Mle, Mycobacterium leprae; Rle, Rhizobium leguminosarum ORF2B; S6803, Synechocystis sp. (strain 6803); S7942, Synechococcus sp. (strain 7942); S8801, Synechococcus sp. (strain 8801); Spo, Schizosaccharomyces pombe; Sty, Salmonella typhimurium; Sxy, Staphylococccus xylosus; Tma, Thermotoga maritima.

analytical tool, none appeared to encode N-terminal secretion signals.

\section{Demonstration of SAT functionality}

To test if pATRLCE13 contains a functional cysE gene, it was transformed into E. coli JM39, a cysE cysteine auxotroph. JM39(pATRLCE13) was able to grow on M9 minimal agar without cystine addition, whereas JM39 containing the parent vector, pTZ18, remained a cysteine auxotroph. To localize the cysE gene more precisely, the PCR was used to amplify the three alternative ORF2s (with pATRLCE13 as the template). Three different $\mathrm{N}$-terminus-encoding primers were used (RLCEM1, RLCEM2 and RLCEM3) together with a common C-terminus-encoding primer (RLCEND1B) to amplify ORFs $2 \mathrm{~A}, 2 \mathrm{~B}$ and $2 \mathrm{C}$, respectively. The amplified DNA segments were cloned between the NdeI and BamHI restriction sites in plasmid pT7-7 in order to exploit the strong translation initiation signals present in this expression vector for potential overexpression and further characterization of the $R$. leguminosarum SAT. The resultant plasmids, pSS1, pSS2 and pSS3, containing ORF2A, ORF2B and ORF2C, respectively, 
were transformed into E. coli JM39. All three plasmids complemented the mutation in JM39 after growth at $37^{\circ} \mathrm{C}$ for $48 \mathrm{~h}$ on $\mathrm{M} 9$ minimal medium. Attempts to overexpress the three ORFs from pSS1, pSS2 and pSS3 in E. coli BL21(DE3) were unsuccessful. The SAT activities of crude extracts of the strains prepared after induction were not significantly above background in any case. This was surprising, since overexpression of CysE from E. coli and from Azotobacter sp. had been obtained in a similar vector/host system. We have observed previously that the minimum levels of SAT activity needed to complement the cysE mutation in JM39 are below the limits of detection of the biochemical assay in crude extracts. The native SAT in R. leguminosarum probably corresponds to the polypeptide of 277 amino acid residues encoded by ORF $2 \mathrm{~B}$, since it is preceded by the best potential ribosome-binding site. The question of the correct translation initiation start can only be resolved by purification and determination of the $\mathrm{N}$ terminal sequence of SAT from $R$. leguminosarum.

\section{Mutagenesis of cysE in $R$. leguminosarum}

The Tn5-lacZ mutants in the cysE gene in cosmid pRU3024 were obtained by random mutagenesis. Plasmids pRU3031 and pRU3033 carry mutations in cysE (see Fig. 1). The mutation in pRU3031 was chosen for further work. Transfer of the insertion into the genome of RU3841 by homogenotization gave strain RU632. We were surprised to find that RU632 exhibited no requirement for cysteine or cystine for growth in the defined medium AMS. This suggests a potential redundancy in cysteine biosynthesis in R. leguminosarum RL3841. We measured enzyme activity in crude extracts prepared from the wild-type strain RU3841 and the mutant RU632. The specific activity for SAT observed in RU3841 was $1.38 \mathrm{nmol}$ (mg protein) ${ }^{-1} \mathrm{~min}^{-1}$, which appears low, at only $17 \%$ of that observed in E. coli (Denk \& Böck, 1987). However, such levels of activity are likely to be more than sufficient to satisfy cysteine needs because the $R$. leguminosarum cysE complemented the cysE mutation in E. coli JM39 even though the levels of SAT activity in extracts of the complemented strain were also below the detection limits of our assay. However, in the mutant, RU632, activity was not detectable above background. We estimated that the minimum detectable activity was not greater than $0 \cdot 08 \mathrm{nmol}\left(\mathrm{mg}\right.$ protein) ${ }^{-1} \mathrm{~min}^{-1}$. These data suggest that the $c y s E$ gene described here accounts for at least $95 \%$ of the SAT activity in R. leguminosarum.

Although we could detect no residual SAT activity in the mutant, a second cysE gene may nevertheless exist, especially since several organisms contain multiple copies of $c y s E$ genes, including A. thaliana, which has four cysE genes (Murillo et al., 1995; Howarth et al., 1997; Bogdanova \& Hell, 1997), and Azotobacter species (which also fix $\mathrm{N}_{2}$ ) in which two cysE genes are known (Evans et al., 1991; Zheng et al., 1998). Therefore, DNA encoding the $c y s E$ gene cloned here was used to probe genomic DNA from R. leguminosarum under a variety of stringencies. In the EcoRI digest, a single $3.4 \mathrm{~kb}$ fragment was identified which probably corresponds to the EcoRI fragment cloned in pATRLCE13. No other hybridizing fragment was present in this digest. In the EcoRI/BamHI double digest, two hybridizing bands were seen: a more intense band at $0.8 \mathrm{~kb}$, and a much less intense band at $1.2 \mathrm{~kb}$. Since the $c y s E$ probe contains a Bam HI site located $65 \mathrm{bp}$ from the $\mathrm{N}$-terminal coding region, it was anticipated that two fragments of different intensities would be detected. Also, the DNA sequence predicts that the probe should detect two EcoRI/BamHI fragments of 1205 and 804 bp, which agrees well with the observed results. Prolonged exposure of the blot and careful scrutiny provided no evidence for the existence of other hybridizing bands in $R$. leguminosarum.

Either a second copy of cysE exists in $R$ leguminosarum RL3841 which is quite divergent from the gene cloned here and is expressed but unstable during extraction and/or assay, or cysteine can be made by a pathway avoiding $\mathrm{O}$-acetylserine. One possibility is that cysteine can be synthesized from methionine; this appears to be the case in Pseudomonas aeruginosa (Foglino et al., 1995) and, more pertinently, Rhizobium etli (Taté et al., 1999). These organisms contain a methioninebiosynthesis pathway, first established for Saccharomyces cerevisiae, in which sulphide is incorporated not into $\mathrm{O}$-acetylserine but into $\mathrm{O}$-succinylhomoserine to form homocysteine, which is converted to methionine. Cysteine is formed from methionine via a transsulphurylation reaction involving cystathionine as an intermediate, obviating the need for $\mathrm{O}$-acetylserine (Cherest \& Surdin-Kerjan, 1992).

\section{Evidence for regulation of the expression of CysE}

The transcriptional activity of the R. leguminosarum $c y s E$ promoter was measured under a number of different growth regimes by following the $\beta$ galactosidase activity arising from the Tn5-lacZ inserted into $c y s E$. The experiments were performed with cosmid- or chromosomal-borne cysE: : Tn5-lacZ fusions (Table 2). There was no significant difference between growth in sulphate-sufficient and sulphate-limited media. However, the nitrogen status influenced the expression of $c y s E$, which was similar in degree in both chromosomal and cosmid-borne fusions. Ammonium, as opposed to glutamate, as a nitrogen source repressed transcription of $c y_{s} E$ by $\sim 50 \%$ in the chromosomal fusion strain RU632, and by $\sim 35 \%$ in the cosmidborne fusion strains RU502 and RU504. However, in an $n t r C$ background, the repression by ammonium was not observed either in the chromosome (strain RU1027) or in the cosmid (strains RU981 and RU982). These results are similar to those obtained previously (Walshaw et al., 1997) for the aap operon, as illustrated here by new data for the aapJ::Tn5-lacZ fusion in the $n t r C^{+}$(strain RU543) and $n t r C^{-}$(strain RU1017) backgrounds. Also, as reported earlier for the aap cluster, the repression of $c y s E$ appears, unusually, to require $\mathrm{NtrC}$, since no 
Table 2. Influence of nitrogen status and $n t r C$ on transcription of the cysE and aapJ genes in R. leguminosarum RL3841, as measured in transcriptional Tn5::lacZ fusions

The data indicate specific activities for $\beta$-galactosidase (expressed as modified Miller units) in cultures of the various strains grown in the presence of the nitrogen sources indicated.

\begin{tabular}{|llcc|}
\hline Strain & \multicolumn{1}{c|}{ Relevant genotype } & $\begin{array}{c}\text { Glucose/ } \\
\mathrm{NH}_{4} \mathrm{Cl}\end{array}$ & $\begin{array}{c}\text { Glucose/ } \\
\text { glutamate }\end{array}$ \\
\hline 3841 & Wild-type & $15 \pm 2$ & $22 \pm 3$ \\
RU929 & $n t r C:: \Omega$ & $27 \pm 1$ & $23 \pm 1$ \\
RU543 & aapJ::Tn5-lacZ & $155 \pm 23$ & $690 \pm 39$ \\
RU1017 & aapJ::Tn5-lacZ & $603 \pm 106$ & $678 \pm 49$ \\
& $n t r C:: \Omega$ & & \\
RU632 & $c y s E:: \operatorname{Tn} 5$-lacZ & $139 \pm 10$ & $269 \pm 23$ \\
RU1027 & $c y s E:: \operatorname{Tn} 5$-lacZ ntrC:: $\Omega$ & $289 \pm 28$ & $309 \pm 44$ \\
RU1013 & $n t r C:: \Omega / c y s E^{+}$ & $34 \pm 1$ & $34 \pm 2$ \\
RU502 (3841/pRU3031) & Wild-type host cysE::Tn5-lacZ & $878 \pm 189$ & $1313 \pm 156$ \\
RU504 (3841/pRU3033) & Wild-type host cysE::Tn5-lacZ & $1325 \pm 103$ & $2096 \pm 103$ \\
RU981 (RU929/pRU3031) & $n t r C:: \Omega$ cysE: $:$ Tn5-lacZ & $1213 \pm 150$ & $1285 \pm 134$ \\
RU982 (RU929/pRU3033) & $n t r C:: \Omega$ cysE::Tn5-lacZ & $2118 \pm 168$ & $2162 \pm 267$ \\
\hline
\end{tabular}

repression by ammonium was observed in an $n t r C^{-}$ background. Since the cysE and aap genes are divergently transcribed, the repressive effects of NtrC appear to be mediated at two independent promoters.

\section{Influence of the cysE mutation on symbiotic nitrogen fixation}

The cysE mutant, RU632, was indistinguishable from the parent strain in its ability to infect and nodulate peas. The mutation was stable in the host, since all 25 isolates from nodules infected with RU632 retained the kanamycin-resistance phenotype associated with the Tn5-lacZ insertion. Rates of $\mathrm{C}_{2} \mathrm{H}_{2}$ reduction for the parent and mutant strains were shown to be $0.45 \pm 0.02$ and $0.83 \pm 0.01 \mu \mathrm{mol} \mathrm{h}^{-1}$ plant $^{-1}$, respectively.

The finding of redundancy in cysteine biosynthesis and of a $c y s E$ gene in proximity to (and subject to) a similar pattern of regulation as the aap genes required for maximal symbiotic $\mathrm{N}_{2}$ fixation in $R$. leguminosarum RL3841 echoes the presence of $c y s E$ genes closely linked to nif genes in other organisms. Of the two cysE genes known for Azotobacter sp., one is intercalated into the major (nif) gene cluster (Evans et al., 1991; Zheng et al., 1998). A cysE gene is located adjacent to nifB in a large cluster of genes for $\mathrm{N}_{2}$ fixation in Synechococcus sp. strain RF-1 (Huang et al., 1999), but as yet there is no evidence for redundancy in cysteine biosynthesis in this cyanobacterium. It has been suggested that the link between cysteine metabolism and $\mathrm{N}_{2}$ fixation may be explained by a high requirement for inorganic sulphur obtained from cysteine for the synthesis of metalsulphur clusters. Alternative or parallel pathways for cysteine biosynthesis may boost the provision of sulphur for the biosynthesis of nitrogenase often present in high levels (Evans et al., 1991). However, deletion of the nifrelated cysE gene in Azotobacter has no marked effects on the development of nitrogenase activity. In $R$. leguminosarum RL3841, it is unclear how the bacteroid obtains sulphur for housekeeping purposes and for the synthesis of nitrogenase, but, like Azotobacter, RU632 (the strain defective in the cysE gene) was unaffected in terms of $\mathrm{N}_{2}$ fixation, though there may be conditions (e.g. nutrient stress) under which a phenotype is expressed.

\section{ACKNOWLEDGEMENTS}

This work was supported, in part, by BBSRC grant CO4183 to R.L.R, and by The Nuffield Foundation (via a Vacation Studentship awarded to K.O.) We also like to thank Liz Pontin and Mike Taylor (both of AMSEQ) for the automated DNA sequencing.

\section{REFERENCES}

Altschul, S. F., Madden, T. L., Schäffer, A. A., Zhang, J., Zhang, Z., Miller, W. \& Lipman, D. J. (1997). Gapped BLAST and PSI-BLAST: a new generation of protein database search programs. Nucleic Acids Res 25, 3389-3402.

Beringer, J. E. (1974). R factor transfer in Rhizobium leguminosarum. J Gen Microbiol 84, 188-198.

Bogdanova, N. \& Hell, R. (1997). Cysteine synthesis in plants: protein-protein interactions of serine acetyltransferase from Arabidopsis thaliana. Plant J 11, 251-262.

Cherest, H. \& Surdin-Kerjan, Y. (1992). Genetic analysis of a new mutation conferring cysteine auxotrophy in Saccharomyces cerevisiae: updating of the sulfur metabolism pathway. Genetics 130, 51-58.

Corpet, F. (1988). Multiple sequence alignment with hierarchical clustering. Nucleic Acids Res 16, 10881-10890.

Denk, D. \& Böck, A. (1987). L-Cysteine biosynthesis in Escherichia coli: nucleotide sequence and expression of the serine acetyl transferase $(c y s E)$ gene from the wild-type and a cysteine excreting mutant. J Gen Microbiol 133, 515-525. 
Evans, D. J., Jones, R., Woodley, P. R., Wilborn, J. R. \& Robson, R. L. (1991). Nucleotide sequence and genetic analysis of the Azotobacter chroococcum nifUSVWZM cluster, including a new gene (nifP) which encodes a serine acetyl transferase. J Bacteriol 173, 5457-5469.

Foglino, M., Borne, F., Bally, M., Ball, G. \& Patte, J. C. (1995). A direct thiolation pathway is used for methionine biosynthesis in Pseudomonas aeruginosa. Microbiology 141, 431-439.

Glenn, A. R., Poole, P. S. \& Hudman, J. F. (1980). Succinate uptake by free-living and bacteroid forms of Rhizobium leguminosarum. J Gen Microbiol 119, 267-271.

Hanahan, D. (1983). Studies on transformation of Escherichia coli with plasmids. J Mol Biol 166, 557-580.

Howarth, J. R., Roberts, M. A. \& Wray, J. L. (1997). Cysteine biosynthesis in higher plants: a new member of the Arabidopsis thaliana serine acetyltransferase small gene-family obtained by functional complementation of an Escherichia coli cysteine auxotroph. Biochim Biophys Acta 1350, 123-127.

Huang, T. C., Lin, R. F., Chu, M. K. \& Chen, H. M. (1999). Organization and expression of nitrogen-fixation genes in the aerobic nitrogen-fixing unicellular cyanobacterium Synechococcus sp. strain RF-1. Microbiology 145, 743-753.

Jones-Mortimer, M. C. (1968). Positive control of sulphate reduction in Escherichia coli. The nature of the pleiotropic cysteineless mutants of E. coli K12. Biochem J 110, 597-602.

Kredich, N. M. (1987). Biosynthesis of cysteine. In Escherichia coli and Salmonella typhimurium: Cellular and Molecular Biology, pp. 419-428. Edited by F. C. Neidhardt and others. Washington, DC: American Society for Microbiology.

Kredich, N. M. \& Tomkins, G. M. (1966). The enzymic synthesis of L-cysteine in Escherichia coli and Salmonella typhimurium. J Biol Chem 241, 4955-4965.

Mead, D. A., Long, S., Ruvkin, G., Brown, S. \& Ausubel, F. (1982). Physical and genetic characterization of symbiotic and auxotrophic mutants of Rhizobium meliloti. J Bacteriol 149, 114-122.

Mead, D. A., Szczesna-Skorupa, E. \& Kemper, B. (1986). Singlestranded DNA 'blue' promoter plasmids: a versatile tandem promoter system for cloning and protein engineering. Protein Eng $1,67-74$.

Miller, J. H. (1972). Experiments in Molecular Genetics, pp. 352-355. Cold Spring Harbor, NY: Cold Spring Harbor Laboratory.

Murillo, M., Foglia, R., Diller, A., Lee, S. \& Leustek, T. (1995). Serine acetyltransferase from Arabidopsis thaliana can functionally complement the cysteine requirement of a cysE mutant strain of Escherichia coli. Cell Mol Biol Res 41, 425-433.

Nielsen, H., Engelbrecht, J., Brunak, S. \& von Heijne, G. (1997). Identification of prokaryotic and eukaryotic signal peptides and prediction of the cleavage sites. Protein Eng 10, 1-6.

Parker, G. F., Higgins, T. P., Hawkes, T. \& Robson, R. L. (1999).
Rhizobium (Sinorhizobium) meliloti phn genes: characterisation and identification of their protein products. J Bacteriol 181, 389-395.

Patriarca, E. J., Riccio, A., Taté, R., Colonna-Romano, S., laccarino, M. \& Defez, R. (1993). The ntrBC genes of Rhizobium leguminosarum are part of a complex operon subject to negative regulation. Mol Microbiol 9, 569-577.

Poole, P. S., Blyth, A., Reid, C. \& Walters, K. (1994a). myo-Inositol catabolism and catabolite regulation in Rhizobium leguminosarum bv. viciae. Microbiology 140, 2787-2795.

Poole, P. S., Schofield, N. A., Reid, C. J., Drew, E. M. \& Walshaw, D. L. (1994b). Identification of chromosomal genes located downstream of $d c t D$ that affect the requirement for calcium and the lipopolysaccharide layer of Rhizobium leguminosarum. Microbiology 140, 2797-2809.

Saitou, N. \& Nei, M. (1987). The neighbour-joining method: a new method for reconstructing phylogenetic trees. Mol Biol Evol 4, 406-425.

Sambrook, J., Fritsch, E. F. \& Maniatis, T. (1989). Molecular Cloning: a Laboratory Manual, 2nd edn. Cold Spring Harbor, NY : Cold Spring Harbor Laboratory.

Studier, F. W. \& Moffatt, B. W. (1986). Use of bacteriophage T7 RNA polymerase to direct selective high-level expression of cloned genes. J Mol Biol 189, 113-130.

Tabor, S. \& Richardson, C. C. (1985). A bacteriophage T7 RNA polymerase/promoter system for controlled exclusive expression of specific genes. Proc Natl Acad Sci U S A 82, 1074-1078.

Taté, R., Riccio, A., Caputo, E., laccarino, M. \& Patriarca, J. (1999). The Rhizobium etli met $Z$ gene is essential for methionine biosynthesis and nodulation of Phaseolus vulgaris. Mol PlantMicrobe Interact 12, 24-34.

Thompson, J. D., Higgins, D. G. \& Gibson, T. J. (1994). CLUSTAL w : improving the sensitivity of progressive multiple sequence alignment through sequence weighting, position-specific gap penalties and weight matrix choice. Nucleic Acids Res 22, 4673-4680.

Trinick, M. J., Dilworth, M. J. \& Grounds, M. (1976). Factors affecting the reduction of acetylene by root nodules of Lupinus species. New Phytol 77, 359-370.

Walshaw, D. L. \& Poole, P. S. (1996). The general L-amino acid permease of Rhizobium leguminosarum is an ABC uptake system that influences efflux of solutes. Mol Microbiol 21, 1239-1252.

Walshaw, D. L., Reid, C. J. \& Poole, P. S. (1997). The general amino acid permease of Rhizobium leguminosarum is negatively regulated by the Ntr system. FEMS Microbiol Lett 152, 57-64.

Zheng, L., Cash, V. L., Flint, D. H. \& Dean, D. R. (1998). Assembly of iron-sulfur clusters. Identification of an iscSUA- $h s c B A-f d x$ gene cluster from Azotobacter vinelandii. J Biol Chem 273, 13264-13272.

Received 15 February 2001; revised 1 June 2001; accepted 12 June 2001. 